\title{
Expression of c-MET in Invasive Meningioma
}

\author{
Sumi Yun · Jae Moon Koh \\ Kyu Sang Lee ${ }^{1} \cdot \mathrm{An} \mathrm{Na} \mathrm{Seo}^{2}$ \\ Kyung Han $\mathrm{Nam}^{3}$ • Gheeyoung Choe \\ Department of Pathology, Seoul National \\ University Hospital, Seoul National University \\ College of Medicine, Seoul; 'Department of \\ Pathology, Seoul National University Bundang \\ Hospital, Seoul National University College of \\ Medicine, Seongnam; '2Department of Pathology, \\ Kyungpook National University Hospital, \\ Kyungpook National University School of \\ Medicine, Daegu; ' ${ }^{3}$ Department of Pathology, \\ Haeundae Paik Hospital, Inje University, Busan, \\ Korea
}

\section{Received: August 29, 2014}

Revised: October 7, 2014

Accepted: October 13, 2014

\section{Corresponding Author}

Gheeyoung Choe, M.D.

Department of Pathology, Seoul National University

Bundang Hospital, Seoul National University College

of Medicine, 82 Gumi-ro 173 Beon-gil, Bundang-

gu, Seongnam 463-707, Korea

Tel: +82-31-787-7711

Fax: +82-31-787-4012

E-mail: gychoe@snu.ac.kr
Background: Meningiomas show high recurrence rates even after curative tumor removal. The invasiveness of meningiomas may contribute to their high recurrence rates. Recently, c-MET and hepatocyte growth factor (HGF) have been reported to be involved in cancer invasion. Methods: We examined the immunohistochemical expression of c-MET and HGF in 100 cases of patients with meningiomas who have undergone complete tumor removal. Results: C-MET-High and HGFHigh were found in $17 \%$ and $13 \%$ of meningiomas, respectively. Brain invasion was observed in $17.6 \%$ of $c-M^{-M^{-H i g h}}$ meningiomas, but in only $2.4 \%$ of $c-M E T^{\text {Low }}$ meningiomas $(p=.033)$. Bone/ soft tissue invasion was observed in $23.5 \%$ of c-MET-High meningiomas and in $9.6 \%$ of c-MET-Low meningiomas $(p=.119)$. HGF-High did not show statistical association with brain invasion or bone/ soft tissue invasion. ${\mathrm{C}-M E T^{-H i g h}}^{-1}$ demonstrated shorter recurrence-free survival (RFS, $93.5 \pm 8.2$ months vs $96.1 \pm 1.9$ months); however, this difference was not statistically significant $(p=.139)$. There was no association of HGF-High with RFS. Conclusions: This study demonstrates that cMET ${ }^{\text {-High }}$ is associated with brain invasion of meningiomas, and that c-MET expression may be a useful predictive marker for meningioma recurrence. Patients with invasive meningiomas with high expressions of c-MET may be good candidates for targeted therapy using c-MET inhibitors.

Key Words: Meningioma; Proto-oncogene proteins c-MET; Hepatocyte growth factor; Neoplasm invasiveness; Immunohistochemistry
Meningioma is a common intracranial tumor arising from the meningothelial (arachnoid) cells. Meningiomas are divided into 15 histologic subtypes and three grades, including benign (grade I), atypical (grade II), and anaplastic (grade III). ${ }^{1}$ Most meningiomas are benign, corresponding to World Health Organization (WHO) grade I, and they have a favorable outcome. Alternatively, grade II atypical meningiomas and grade III anaplastic meningiomas have less favorable outcomes. ${ }^{2,3}$ Even in benign cases, meningiomas have high recurrence rates after curative surgical treatment. They have been estimated to recur in $7 \%-25 \%$, $29 \%-52 \%$, and $50 \%-94 \%$ of cases in grades I, II, and III, respectively. ${ }^{4}$

Several markers, such as the proliferation index, the vascular density marker, and the expression of sex hormone receptors, are suggested for predicting the recurrence rates of tumors. Howev- er, it is generally accepted that both histopathological features, including histologic subtypes and clinical data, have limitations in their use as reliable markers for predicting tumor recurrence due to low accuracy. ${ }^{5-8}$ Previous studies report an association among meningiomas, brain or bone invasion, and higher tumor recurrence rates. However, the mechanism of invasion has not been well established. ${ }^{9-12}$

Also called a hepatocyte growth factor (HGF), c-MET is a receptor tyrosine kinase that, upon binding of its ligand, is phosphorylated. Subsequently, c-MET activates the signaling pathway of cell proliferation and migration. The c-MET/HGF signaling pathway was first described as an oncogene in the 1980s. Accordingly, it has been known to induce tumor cell proliferation, motility, and invasion, as well as to promote angiogenesis in several human cancers, such as breast, lung and hepatocellular 
carcinomas. ${ }^{13-16}$ In meningiomas, the expression of c-MET/HGF has been reported to have a diverse relationship with tumor recurrence, angiogenesis, histologic subtypes, and the invasiveness of the meningioma. Existing reports are based on a limited number of samples and different methods, such as enzymelinked immunosorbent assay, immunohistochemistry or reverse transcription polymerase chain reaction (RT-PCR). ${ }^{17-19}$ To date, little is known about their expression in invasive meningiomas. The aim of this study, therefore, is to elucidate whether the protein expressions of c-MET and HGF are associated with clinicopathologic variables, as well as brain and bone/soft tissue invasion of meningiomas, in large scale studies of meningioma.

\section{MATERIALS AND METHODS}

\section{Meningioma cases}

Formalin-fixed, paraffin-embedded archival tissue samples from 100 patients who underwent complete surgical resection (Simpson grade I) of meningiomas between August 2003 and December 2012 were collected from the databases of the Department of Pathology, Seoul National University Bundang Hospital in Korea. Clinical and pathological data were obtained by reviewing medical records and pathology reports. Two pathologists (G.C. and S.Y.) independently reviewed the hematoxylin and eosin-stained slides, confirmed the diagnosis according to the 2007 WHO classification system, and classified the histological subtypes and grading of the meningiomas. All the patients received regular follow-up after surgery, without postoperative chemoradiation therapy. The recurrence-free survival (RFS) was calculated from the time of surgery to the first suspected recurrence of meningioma. Evidence of tumor recurrence was provided by a computed tomography scan or a magnetic resonance image showing a meningioma in a location contiguous with the previous operation site.

\section{Demographic data}

The clinicopathologic features of patients are summarized in Table 1. The 100 patients consisted of 23 males (23\%) and 77 females $(77 \%)$, with median age of 60 years (range, 36 to 85 years). Of these, bone/soft tissue invasion was observed in 12 cases, brain invasion was observed in five cases, and both bone/soft tissue invasion and brain invasion were observed in one case. We defined "soft tissue invasion" as invasion of the meningioma to the scalp or paranasal sinus. According to the 2007 WHO classification, all were cases of benign meningiomas (grade I). Histologically, the 100 cases consisted of meningothelial types
Table 1. Clinicopathologic characteristics of meningioma cases

\begin{tabular}{lc}
\hline Characteristic & No. \\
\hline Meadian age (range, yr) & 60 (36-85) \\
Sex & \\
Male & 23 \\
Female & 77 \\
Histologic subtype & \\
Meningothelial & 32 \\
Transitional & 32 \\
Fibrous & 16 \\
Angiomatous & 13 \\
Psammomatous & 2 \\
Microcystic & 4 \\
Metaplastic & 1 \\
\hline
\end{tabular}

( $n=32)$, transitional types $(n=32)$, fibrous types $(n=16)$, angiomatous types ( $n=13)$, psammomatous types $(n=2)$, microcystic types $(n=4)$, and one metaplastic type $(n=1)($ Table 1$)$.

\section{Construction of tissue microarray}

We chose one representative tumor block in each case, and harvested cores with diameters of $3 \mathrm{~mm}$ from the most representative tumor areas of the donor blocks. The cores were precisely arranged into new recipient tissue microarray (TMA) blocks using a trephine apparatus according to previously described protocols. $^{20}$

\section{Immunohistochemistry staining and interpretation}

Immunohistochemical staining was carried out using TMA according to a previously described method. ${ }^{20}$ Briefly, sections of $4 \mu \mathrm{m}$ were transferred to poly-L-lysine coated adhesive slides and dried, deparaffinized, and rehydrated. The slides were subsequently subjected to heat-induced antigen retrieval. The following antibodies were used according to manufacturer instruction: c-MET (pre-dilution, rabbit monoclonal antibody, Ventana Medical Systems, Inc., Tucson, AZ, USA) and HGFa (1:100, rabbit polyclonal antibody, Santa Cruz Biotechnology, Santa Cruz, CA, USA). The sections were incubated with appropriate reagents from the Dako REAL EnVision Detection System (DAKO, Glostrup, Denmark), and were counterstained with Mayer's hematoxylin. Evaluation of c-MET and HGF expression was assessed according to previous reports. ${ }^{21}$ As a positive control for c-MET and HGF, tubular cells of a normal kidney and normal colonic mucosa were used, respectively. Immunostaining without the primary antibody was used as the negative control. Each case was categorized as positive when it showed moderateto-strong cytoplasmic and/or membranous positivity in tumor cells. Accordingly, we scored expression as c-MET ${ }^{\text {High }}$ and $\mathrm{HGF}^{-}$ High ( $>25 \%$ positive cells) and c-MET ${ }^{\text {Low }}$ and HGF $^{- \text {Low }}(0 \%-25 \%$ 
tumor cells) (Fig. 1). ${ }^{22}$

\section{Ethics statements}

The study was conducted according to the ethics standards of the World Medical Association's Declaration of Helsinki.

\section{Statistical analysis}

All statistical analyses were conducted using the SPSS ver. 21.0 (IBM Co., Armonk, NY, USA). Associations between the protein expressions of each antibody and the categorical variables were assessed using chi-square tests or Fisher exact tests, if ap-
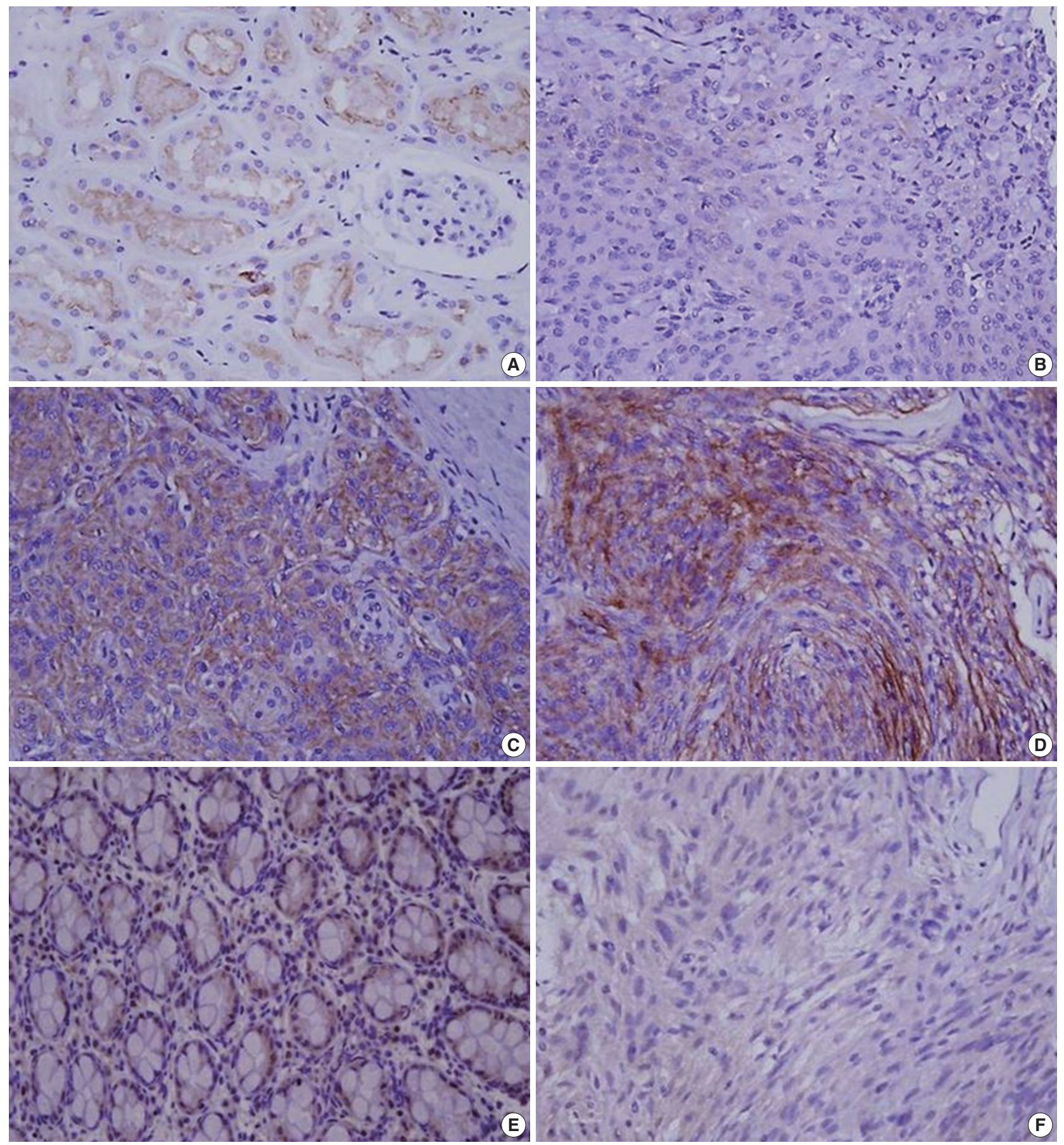

Fig. 1. Immunohistochemical staining in meningiomas. (A) C-MET staining in tubular cells in normal kidney. (B) c-MET weak staining in meningioma. (C) c-MET moderate staining in meningioma. (D) C-MET strong staining in meningioma. (E) Hepatocyte growth factor (HGF) staining in colonic mucosa. (F) HGF weak staining in meningioma.

(Continued to the next page) 

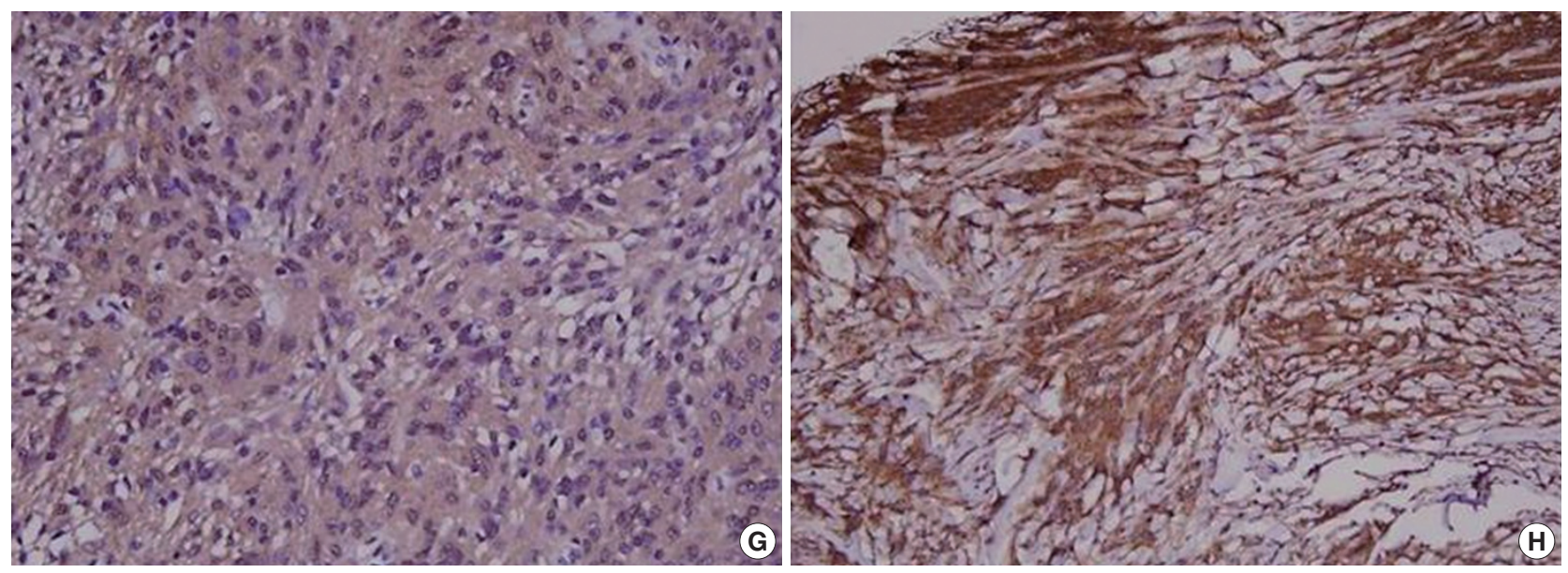

Fig. 1. (Continued) (G) HGF moderate staining in meningioma. (H) HGF strong staining in meningioma.

Table 2. Summary of brain and bone/soft tissue invasion in meningiomas

\begin{tabular}{|c|c|c|c|c|c|c|}
\hline \multirow{2}{*}{ Characteristic } & \multicolumn{3}{|c|}{ Brain invasion } & \multicolumn{3}{|c|}{ Bone/soft tissue invasion } \\
\hline & Yes $(n=5)$ & No $(n=95)$ & $p$-value & Yes $(n=12)$ & No $(n=88)$ & $p$-value \\
\hline Age (yr) & $73(47-77)$ & $60(36-85)$ & - & $58(42-75)$ & $60(36-85)$ & - \\
\hline \multicolumn{7}{|l|}{ Sex } \\
\hline Male & $3(13.0)$ & $20(87.0)$ & .078 & $2(8.7)$ & $21(91.3)$ & .728 \\
\hline Female & $2(2.6)$ & $75(97.4)$ & & $10(13.0)$ & $67(87.0)$ & \\
\hline
\end{tabular}

Values are presented as median (range) or number (\%).

propriate. Kaplan-Meier survival curves for RFS were plotted for each antibody, and the survival comparison was determined using log rank tests. All tests were two-tailed, and statistical significance was set as $\mathrm{p}<.05$.

\section{RESULTS}

\section{Clinical characteristics according to brain invasion and bone/soft tissue invasion}

Among the 100 cases of meningiomas, brain invasion was observed in five cases (5\%). The median age of cases with brain invasion was 73 years (range, 47 to 77 years). Additionally, 13\% (3/23) of male patients presented with brain invasion, and 2.6\% (2/77) of female patients presented with brain invasion. Therefore, brain invasion was found to be more common in male patients. Even in male patients, however, statistical significance was not reached $(\mathrm{p}=.078)$. Bone and/or soft tissue invasion was observed in 12 cases of meningiomas, consisting of two males $(8.7 \%, 2 / 23)$ and 10 females $(13 \%, 10 / 77)$. Therefore, there was no significant association between bone/soft tissue invasion and sex $(p=.728)$. The median age of patients with bone/soft tissue invasion was 58 years (range, 42 to 75 years) (Table 2).

\section{Expression of c-MET and HGF in meningiomas according} to histologic subtypes

Of the cases, c-MET ${ }^{\text {High }}$ and $\mathrm{HGF}^{-\mathrm{High}}$ were found in $17 \%$ $(17 / 100)$ and $13 \%(13 / 100)$ of meningiomas, respectively, and

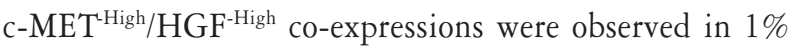
$(1 / 100)$ of meningiomas. c-MET ${ }^{\text {High }}$ and $\mathrm{HGF}^{-\mathrm{High}}$ showed no significant correlation with the histologic subtypes of meningiomas (Table 3).

\section{Association of the expression of c-MET and HGF with brain invasion}

Brain invasion was observed in 3/17 (17.6\%) of c-MET ${ }^{\text {High }}$ meningiomas and in 2/83 (2.4\%) of c-MET ${ }^{\mathrm{L} \text { Low }}$ meningiomas. Therefore, there was a statistically significant correlation between c-MET ${ }^{\text {High }}$ and brain invasion $(\mathrm{p}=.033)$. Neither HGF ${ }^{- \text {High }}$ nor c-MET ${ }^{\text {High }} / \mathrm{HGF}^{- \text {High }}$ co-expression showed statistical associations with brain invasion ( $\mathrm{p}=.375$ and $\mathrm{p}=.562$, respectively) (Table 4).

\section{Association of the expression of c-MET and HGF with bone/soft tissue invasion}

Of the cases, bone/soft tissue invasion was observed in 4/17 (23.5\%) of c-MET ${ }^{\text {High }}$ meningiomas and in 8/83 (9.6\%) of cMET $^{\text {Low }}$ meningiomas. There was a tendency for $\mathrm{c}-\mathrm{MET}^{\mathrm{High}}$ 
Table 3. Expression of C-MET and HGF in meningiomas according to histologic subtypes

\begin{tabular}{lccc}
\hline Histologic subtype & c-MET-High & HGF-High & c-MET-High/HGF-High \\
\hline Meningothelial $(n=32)$ & $10(31.3)$ & $6(18.8)$ & $4(12.5)$ \\
Transitional $(n=32)$ & $1(3.1)$ & $3(9.4)$ & 0 \\
Fibrous $(n=16)$ & $3(18.8)$ & $2(12.5)$ & $1(6.3)$ \\
Angiomatous $(n=13)$ & $2(15.4)$ & $1(7.7)$ & 0 \\
Psammomatous $(n=1)$ & 0 & 0 & 0 \\
Microcystic $(n=4)$ & $1(25.0)$ & $1(25.0)$ & $1(25.0)$ \\
Metaplastic $(n=1)$ & 0 & 0 & 0
\end{tabular}

Values are presented as number (\%).

HGF, hepatocyte growth factor.

Table 4. Association of the expression of c-MET and HGF with brain invasion and bone/soft tissue invasion

\begin{tabular}{|c|c|c|c|c|c|c|}
\hline & \multicolumn{2}{|c|}{ Brain invasion } & \multirow{2}{*}{$p$-value } & \multicolumn{2}{|c|}{ Bone/soft tissue invasion } & \multirow{2}{*}{$\mathrm{p}$-value } \\
\hline & Negative & Positive & & Negative & Positive & \\
\hline \multicolumn{7}{|c|}{ c-MET $(n=100)$} \\
\hline C-MET-Low & 81 & 2 & .033 & 75 & 8 & .119 \\
\hline C-MET-High & 14 & 3 & & 13 & 4 & \\
\hline \multicolumn{7}{|c|}{$\operatorname{HGF}(n=100)$} \\
\hline HGF-Low & 82 & 5 & .375 & 77 & 10 & .653 \\
\hline HGF-High & 13 & 0 & & 11 & 2 & \\
\hline \multicolumn{7}{|c|}{ c-MET-High/HGF-High $(n=100)$} \\
\hline Negative & 89 & 5 & .562 & 84 & 10 & .151 \\
\hline Positive & 6 & 0 & & 4 & 2 & \\
\hline
\end{tabular}

HGF, hepatocyte growth factor.

meningiomas to show bone/soft tissue invasion more frequently than $\mathrm{c}-\mathrm{MET}^{\mathrm{L}}{ }^{\mathrm{Low}}$ meningiomas; however, statistical significance was not reached $(\mathrm{p}=.119)$. Additionally, bone/soft tissue invasion was found in $15.4 \%(2 / 13)$ of $\mathrm{HGF}^{-\mathrm{High}}$ meningioma and

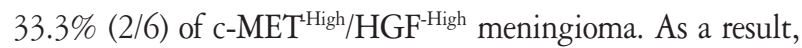
$\mathrm{HGF}^{-\mathrm{High}}$ and c-MET ${ }^{\mathrm{High}} / \mathrm{HGF}^{-\mathrm{High}}$ co-expressions did not show a significant association with bone/soft tissue invasion $(\mathrm{p}=.653$ and $\mathrm{p}=.151$, respectively).

\section{Tumor RFS according to c-MET and HGF expressions}

To identify whether the complete removal of meningiomas from patients differently impacts RFS periods depending on the status of c-MET and HGF expressions, we performed a univariate analysis of 100 cases of Simpson grade I meningiomas. In the current study, the median follow-up period was 26.7 months (range, 1.1 to 106.2 months). Four cases (4\%) suffered tumor recurrence.

Among the 17 cases with c-MET ${ }^{\text {High }}$, two cases $(11.8 \%)$ experienced recurrence, whereas two of 83 cases $(2.4 \%)$ with cMET $^{\text {Low }}$ suffered recurrence. Cases with $\mathrm{c}^{-M^{2}}{ }^{\text {High }}$ showed shorter RFS periods (mean \pm standard deviation [SD], 93.5 \pm 8.2 months) than those of $c-M^{- \text {Low }}$ (mean \pm SD, 96.1 \pm 1.9 months); however, statistical significance was not reached $(\mathrm{p}=.139) . \mathrm{HGF}^{-\mathrm{High}}$ and $\mathrm{c}-\mathrm{MET}^{\mathrm{High}} / \mathrm{HGF}^{-\mathrm{High}}$ were not correlat- ed with RFS according to our results (Fig. 2).

\section{DISCUSSION}

We set out to determinate whether the expression of c-MET and HGF is associated with the invasiveness of meningiomas and their clinical implications. In the present study, c-MET ${ }^{\text {High }}$ correlated with brain invasion and bone/soft tissue invasion. To the best of our knowledge, this is the first large scale report on meningiomas in East Asian patients.

The protein known as c-MET is a receptor tyrosine kinase (RTK), and is a well-known proto-oncogene that is expressed in many organs, including the liver, pancreas, and prostate. In development and wound tissue, c-MET regulates many cellular processes, including cell proliferation, motility and cell survival. HGF is the known ligand of the c-MET RTK. ${ }^{13-15}$ Previous studies demonstrate that the c-MET/HGF signaling pathway, as well as c-MET overexpression, has a strong relationship with tumor cell proliferation, motility, invasion, tumor angiogenesis, and poor prognosis. A therapeutic agent targeting c-MET and HGF is currently receiving attention. ${ }^{13,15}$ Meningiomas, as previously described, show high recurrence rates, even after curative resection of the tumors. The recurrence rate depends on several prognostic factors, including the invasiveness of the tu- 

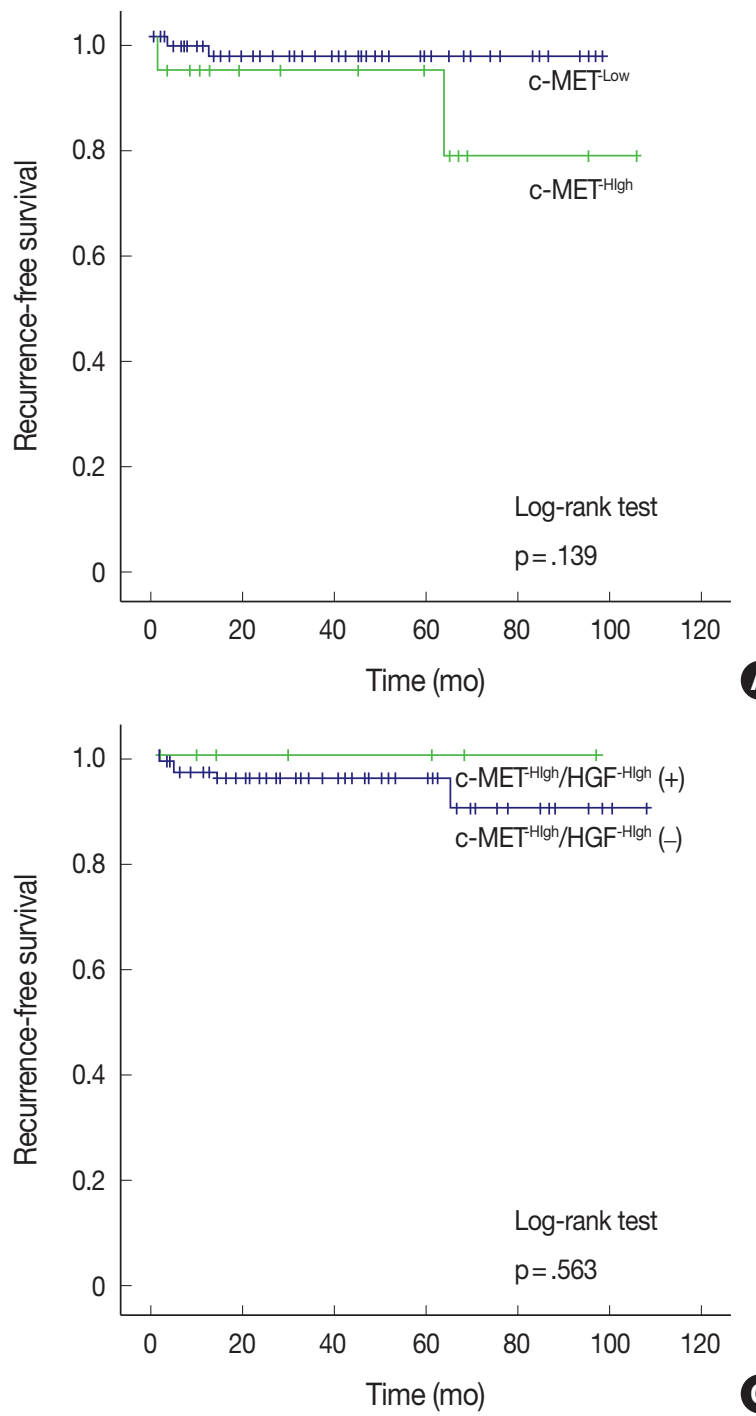

mor. Because invasive meningiomas show poor prognosis, the identification of their mechanism may be useful in the management of meningiomas. ${ }^{23,24}$ Several studies identify an association of c-MET/HGF expression and clinical significance, and most of these studies imply an association between c-MET/HGF expression and tumor recurrence in meningioma. In MartinezRumayor et al.'s study, ${ }^{17}$ immunohistochemical co-expression of c-MET/HGF is related to cell proliferation and the recurrence of meningiomas. Kim et al. ${ }^{19}$ also shows that the expression of HGF and the co-expression of c-MET/HGF are associated with the histologic grade of and recurrence of meningiomas by RTPCR. In contrast, studies by Karja et al. ${ }^{3}$ and Lamszus et al..$^{18}$ use enzyme-linked immunosorbent assay and immunohistochemistry to argue that HGF is not related to tumor recurrence in meningioma. ${ }^{3,21}$ Few studies demonstrate an association of cMET/HGF with brain and bone invasion of meningiomas. The

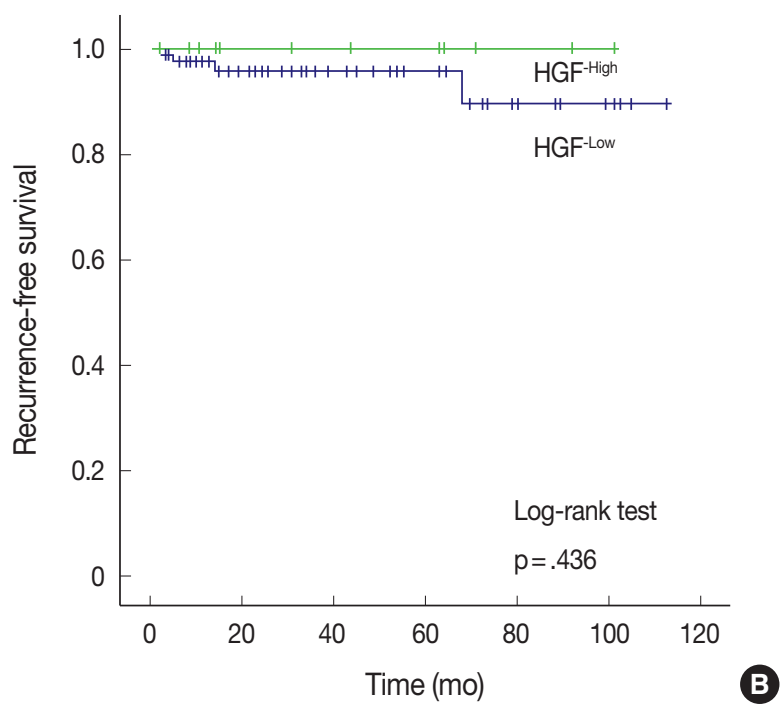

Fig. 2. Kaplan-Meier curves for recurrence-free survival according to the expression of c-MET and hepatocyte growth factor (HGF). (A) Analysis by c-MET expression status. (B) Analysis by HGF expression status. (C) Analysis by c-MET/HGF co-expression status.

present study provides data on the expression of c-MET and HGF in a large scale studies of meningiomas, as well as on the relationships of the meningiomas with brain and bone/soft tissue invasion in patients. In addition, the study shows that cMET $^{\text {High }}$ is significantly associated with meningioma brain invasion, and that there is a tendency for increased c-MET ${ }^{\text {High }}$ in meningiomas with bone/soft tissue invasion. However, $\mathrm{HGF}^{-}$ High does not show any significant association with the invasiveness of meningiomas. Recent studies reveal that the c-MET signaling cascade facilitates the invasion of cancer. The downstream cascade signaling of activated c-MET, by either autocrine or paracrine interaction, leads to the dissociation of tumor cells from the surrounding stromal tissue, resulting in tumor cell invasion. ${ }^{13,14,25}$ Our study supports these findings that cMET is closely related to tumor invasion. One limitation of this study is that only a few cases of rare specific histologic subtypes 
are included in the data. Nevertheless, the results suggest that c-MET may participate in tumor invasion.

We also evaluate a possible association between the c-MET and HGF expression and disease recurrence. In this study, the recurrence rate of meningiomas with complete tumor resection is $5 \%$, a finding which is slightly lower than findings in previous reports. ${ }^{26}$ Also, we demonstrate that c-MET ${ }^{\text {High }}$ only shows a tendency for association with shorter RFS periods. In general, the recurrence of meningiomas occurred within two years of surgical treatment, and up to $94 \%$ of patients with meningiomas experienced recurrence within five years. ${ }^{27}$ However, the vast majority of meningiomas are slow-growing tumors, and benign meningiomas that have been completely removed from patients recur at a rate of $19 \%$ after 20 years of follow-up. ${ }^{28}$ Thus our findings about recurrence rates are limited due to an insufficient follow-up period (median follow-up time in this study, 26.7 months). Several studies report an intratumoral heterogeneity of c-MET and HGF expression, revealing an increase in these factors at cancer-invading fronts in breast carcinoma and cholangiocarcinoma. ${ }^{29,30}$ Accordingly, further studies are needed to elucidate intratumoral heterogeneity in meningiomas, and the association between c-MET overexpression and RFS.

In summary, our results demonstrate that c-MET is associated with the brain invasion of meningiomas, and that c-MET expression may be useful predictive markers for meningioma recurrence.

Many previous studies reveal that c-MET signaling is involved in the progression and spread of several cancers. ${ }^{16-19,25,28}$ The collective understanding of c-MET's role in cancers has evoked considerable interest in c-MET and HGF as major targets in the development of cancer drugs. This has led to the development of a variety of c-MET pathway antagonists with potential clinical applications. Several c-MET antagonists are now under clinical investigation. ${ }^{13,14,25}$ We conclude that c-MET expression may be a useful predictive marker for meningioma recurrence, and that invasive meningiomas with high expression of c-MET may be good candidates for targeted therapy using selective c-MET inhibitors.

\section{Conflicts of Interest}

No potential conflict of interest relevant to this article was reported.

\section{REFERENCES}

1. Louis DN, Ohgaki H, Wiestler OD, Cavenee WK. WHO classification of tumours of the central nervous system. Lyon: IARC Press,
2007.

2. Choy W, Kim W, Nagasawa D, et al. The molecular genetics and tumor pathogenesis of meningiomas and the future directions of meningioma treatments. Neurosurg Focus 2011; 30: E6.

3. Karja V, Sandell PJ, Kauppinen T, Alafuzoff I. Does protein expression predict recurrence of benign World Health Organization grade I meningioma? Hum Pathol 2010; 41: 199-207.

4. Perry A, Stafford SL, Scheithauer BW, Suman VJ, Lohse CM. Meningioma grading: an analysis of histologic parameters. Am J Surg Pathol 1997; 21: 1455-65.

5. Ildan F, Erman T, Göçer AI, et al. Predicting the probability of meningioma recurrence in the preoperative and early postoperative period: a multivariate analysis in the midterm follow-up. Skull Base 2007; 17: 157-71.

6. Durand A, Labrousse F, Jouvet A, et al. WHO grade II and III meningiomas: a study of prognostic factors. J Neurooncol 2009; 95: 367-75.

7. Caltabiano R, Barbagallo GM, Castaing M, et al. Prognostic value of EGFR expression in de novo and progressed atypical and anaplastic meningiomas: an immunohistochemical and fluorescence in situ hybridization pilot study. J Neurosurg Sci 2013; 57: 139-51.

8. Barresi V, Vitarelli E, Tuccari G, Barresi G. MMP-9 expression in meningiomas: a prognostic marker for recurrence risk? J Neurooncol 2011; 102: 189-96.

9. Fathi AR, Roelcke U. Meningioma. Curr Neurol Neurosci Rep 2013; 13: 337.

10. Alahmadi H, Croul SE. Pathology and genetics of meningiomas. Semin Diagn Pathol 2011; 28: 314-24.

11. Terzi A, Saglam EA, Barak A, Soylemezoglu F. The significance of immunohistochemical expression of Ki-67, p53, p21, and p16 in meningiomas tissue arrays. Pathol Res Pract 2008; 204: 305-14.

12. Kliese N, Gobrecht P, Pachow D, et al. miRNA-145 is downregulated in atypical and anaplastic meningiomas and negatively regulates motility and proliferation of meningioma cells. Oncogene 2013; 32: 4712-20

13. Liu X, Newton RC, Scherle PA. Developing c-MET pathway inhibitors for cancer therapy: progress and challenges. Trends Mol Med 2010; 16: 37-45

14. Guessous F, Zhang Y, diPierro C, et al. An orally bioavailable c-Met kinase inhibitor potently inhibits brain tumor malignancy and growth. Anticancer Agents Med Chem 2010; 10: 28-35.

15. Organ SL, Tsao MS. An overview of the c-MET signaling pathway. Ther Adv Med Oncol 2011; 3(1 Suppl): S7-19.

16. Feng Y, Thiagarajan PS, Ma PC. MET signaling: novel targeted inhibition and its clinical development in lung cancer. J Thorac Oncol 2012; 7: 459-67. 
17. Martínez-Rumayor A, Arrieta O, Guevara P, et al. Coexpression of hepatocyte growth factor/scatter factor (HGF/SF) and its receptor cMET predict recurrence of meningiomas. Cancer Lett 2004; 213: $117-24$.

18. Lamszus K, Lengler U, Schmidt NO, Stavrou D, Ergün S, Westphal M. Vascular endothelial growth factor, hepatocyte growth factor/ scatter factor, basic fibroblast growth factor, and placenta growth factor in human meningiomas and their relation to angiogenesis and malignancy. Neurosurgery 2000; 46: 938-47.

19. Kim NR, Chae YS, Lim WJ, Cho SJ. Expression of hepatocyte growth factor/c-met by RT-PCR in meningiomas. Korean J Pathol 2011; 45: 463-8.

20. Suh JH, Park JW, Lee C, Moon KC. ERG immunohistochemistry and clinicopathologic characteristics in Korean prostate adenocarcinoma patients. Korean J Pathol 2012; 46: 423-8.

21. Bozkaya G, Korhan P, Cokakli M, et al. Cooperative interaction of $\mathrm{MUC1}$ with the $\mathrm{HGF} / \mathrm{c}-\mathrm{Met}$ pathway during hepatocarcinogenesis. Mol Cancer 2012; 11: 64.

22. Kong DS, Song SY, Kim DH, et al. Prognostic significance of c-Met expression in glioblastomas. Cancer 2009; 115: 140-8

23. Palma L, Celli P, Franco C, Cervoni L, Cantore G. Long-term prognosis for atypical and malignant meningiomas: a study of 71 surgi- cal cases. J Neurosurg 1997; 86: 793-800.

24. Gabeau-Lacet D, Aghi M, Betensky RA, Barker FG, Loeffler JS, Louis DN. Bone involvement predicts poor outcome in atypical meningioma. J Neurosurg 2009; 111: 464-71.

25. Eder JP, Vande Woude GF, Boerner SA, LoRusso PM. Novel therapeutic inhibitors of the c-Met signaling pathway in cancer. Clin Cancer Res 2009; 15: 2207-14.

26. Yamasaki F, Yoshioka H, Hama S, Sugiyama K, Arita K, Kurisu K. Recurrence of meningiomas. Cancer 2000; 89: 1102-10.

27. Violaris K, Katsarides V, Sakellariou P. The recurrence rate in meningiomas: analysis of tumor location, histological grading, and extent of resection. Open J Mod Neurosurg 2011; 2: 6-10.

28. Jääskeläinen J. Seemingly complete removal of histologically benign intracranial meningioma: late recurrence rate and factors predicting recurrence in 657 patients: a multivariate analysis. Surg Neurol 1986; 26: 461-9.

29. Edakuni G, Sasatomi E, Satoh T, Tokunaga O, Miyazaki K. Expression of the hepatocyte growth factor/c-Met pathway is increased at the cancer front in breast carcinoma. Pathol Int 2001; 51: 172-8.

30. Terada T, Nakanuma Y, Sirica AE. Immunohistochemical demonstration of MET overexpression in human intrahepatic cholangiocarcinoma and in hepatolithiasis. Hum Pathol 1998; 29: 175-80. 